\title{
RESEARCH
}

Open Access

\section{Reclassification of tumor size for solitary HBV-related hepatocellular carcinoma by minimum $p$ value method: a large retrospective study}

Hongzhi Liu ${ }^{1,2+}$, Yuan Yang ${ }^{3 \dagger}$, Chuanchun Chen ${ }^{4}$, Lei Wang ${ }^{1}$, Qizhen Huang ${ }^{1}$, Jianxing Zeng ${ }^{1,2}$, Kongying Lin ${ }^{1,2}$, Yongyi Zeng ${ }^{1,2}$, Pengfei Guo ${ }^{1}$, Weiping Zhou ${ }^{3^{*}}$ and Jingfeng Liu ${ }^{1,2^{*}}$

\begin{abstract}
Background and objectives: Tumor size is one of the most important issues for hepatocellular carcinoma (HCC) treatment and prognosis, but the classification of it is still controversial. The aim of this study was to screen appropriate cutoffs for size of solitary hepatitis B virus (HBV)-related HCC.

Methods: A cohort of 1760 patients with solitary HBV-related HCC undergoing curative liver resection was divided into 11 groups based on tumor size in 1-cm interval. The minimum $p$ value method was used to screen the appropriate size cutoff according to overall survival (OS). If multiple cutoffs meet the above standard, a univariate analysis will be performed by using the Cox proportional hazards regression model, and hazard ratio (HR) will be considered as a criterion to assess the difference in survival.

Results: There are 8 dichotomy, 8 trichotomy, and no inquartation cutoffs that were screened when classifying tumor sizes in accordance with OS. The HR values of tumor size at these trichotomy cutoffs for OS were compared, and the highest HR value is 2.79 when size cutoff is $3 / 9 \mathrm{~cm}$. Then, we reclassified patients into three new classifications: $\leq 3 \mathrm{~cm}(n=422),>3$ and $\leq 9 \mathrm{~cm}(n=1072)$, and $>9 \mathrm{~cm}(n=266)$. The comparison of clinicopathologic characteristics among these three classifications showed that the increase of tumor size was associated with the increase of a-fetoprotein (AFP), microvascular invasion (MVI), tumor differentiation, and liver cirrhosis. And the comparison of the OS among three classifications showed statistical differences.

Conclusions: This study suggested that size criteria of $3 \mathrm{~cm}$ and $9 \mathrm{~cm}$ in solitary HBV-related HCC patients were appropriate based on biological characteristics and prognostic significance.
\end{abstract}

Keywords: Hepatocellular carcinoma, Solitary, Tumor size, Prognosis

\footnotetext{
*Correspondence: ehphwp@126.com; drjingfeng@126.com

${ }^{\dagger}$ Hongzhi Liu and Yuan Yang contributed equally to this work.

${ }^{3}$ Department of Hepatobiliary Surgery, Eastern Hepatobiliary Surgery Hospital,

Second Military Medical University, Changhai Street 225, Shanghai 200438,

People's Republic of China

${ }^{1}$ Southeast Big Data Institute of Hepatobiliary Health, Mengchao

Hepatobiliary Hospital of Fujian Medical University, Fuzhou 350025, People's

Republic of China

Full list of author information is available at the end of the article
}

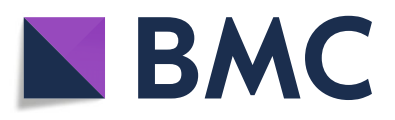

(- The Author(s). 2020 Open Access This article is licensed under a Creative Commons Attribution 4.0 International License, which permits use, sharing, adaptation, distribution and reproduction in any medium or format, as long as you give appropriate credit to the original author(s) and the source, provide a link to the Creative Commons licence, and indicate if changes were made. The images or other third party material in this article are included in the article's Creative Commons licence, unless indicated otherwise in a credit line to the material. If material is not included in the article's Creative Commons licence and your intended use is not permitted by statutory regulation or exceeds the permitted use, you will need to obtain permission directly from the copyright holder. To view a copy of this licence, visit http://creativecommons.org/licenses/by/4.0/. The Creative Commons Public Domain Dedication waiver (http://creativecommons.org/publicdomain/zero/1.0/) applies to the data made available in this article, unless otherwise stated in a credit line to the data. 


\section{Introduction}

Hepatocellular carcinoma (HCC) is the second leading cause of cancer-related death in the world $[1,2]$. Due to the high prevalence of hepatitis B virus (HBV) infection, the incidence of HCC in China alone accounts for about 55\% cases globally [3]. Currently, liver resection (LR) is regarded as first-line treatment for HCC. Unfortunately, outcomes after resection are still suboptimal [4, 5]. Tumor size has been taken into account to be a poor-prognosis factor for HCC after LR, and it has been included in multiple HCC staging systems. However, there is no consensus regarding the cutoff criteria of size for the solitary HCC at present.

Many previous studies tend to focus on the cutoff of size for small HCC tumor alone or single large $\mathrm{HCC}$ tumor which is $>5 \mathrm{~cm}$ [6-9]. Some studies analyzed solitary HCC of full size and screened size cutoffs based on overall survival (OS) [10-12]. However, the tumor size cutoff results are inconsistent. In addition, lots of studies showed tumor size of $2 \mathrm{~cm}, 3$ $\mathrm{cm}$, and $5 \mathrm{~cm}$ could be the criterion of small HCC and many studies showed tumor size of $5 \mathrm{~cm}, 7 \mathrm{~cm}, 8$ $\mathrm{cm}$, and $10 \mathrm{~cm}$ could be independent predictors of death after LR [10]. These findings call for appropriate methods to distinguish the tumor size of solitary HCC.

The method of minimum $p$ value can be used to distinguish the quantitative indexes by the prognostic outcome $[13,14]$, and it has been used to classify tumor sizes in a multicenter study [12]. The present study employed the minimum $p$ value method to investigate whether patients with solitary HBV-related HCC of different sizes differed significantly in OS after LR, and screen appropriate cutoffs of size for solitary HBVrelated HCC.

\section{Patients and methods Study cohort}

This study was conducted under the guideline of the 1975 Declaration of Helsinki and was approved by the Institutional Ethics Committee of the Mengchao Hepatobiliary Hospital of Fujian Medical University. Informed consent obtained from all patients was written before LR operation. Medical records of HCC patients from June 2008 to December 2014 were extracted from primary liver cancer big data (PLCBD) [15]. Data were extracted by an engineer and were verified by five researchers in this study.

The inclusion criteria were as follows: (1) solitary HCC tumor, (2) Child-Pugh A or B liver function, (3) seropositive for HBV surface antigen ( $\mathrm{HBsAg}$ ) and seronegative for hepatitis $\mathrm{C}$ virus antibody (HCV-Ab), and (4) underwent curative hepatectomy. Exclusion criteria were as follows: (1) having received any preoperative anticancer treatments; (2) had a history of other cancers; (3) HCC caused by other reasons such as hepatitis C virus $(\mathrm{HCV})$, alcohol consumption, and cryptogenic disease; and (4) pathological and clinical data are incomplete. Finally, 1760 patients were selected as the study cohort.

\section{Study design}

To examine possible subclassification of solitary HCC, HCCs with the largest tumor diameters $\leq 10 \mathrm{~cm}$ were divided into ten groups with $1-\mathrm{cm}$ intervals, and HCCs with the largest tumor diameters $>10 \mathrm{~cm}$ were selected as one group. There were 10, 45, and 120 cutoffs of size when classifying our patients into dichotomy, trichotomy, and inquartation groups respectively. The rationale for adopting the appropriate cutoff value for solitary HBV-related HCC was confirmed by the minimum $p$ value approach to predict OS after LR.

The OS rates were generated by using the KaplanMeier method, and the differences were compared by log-rank test. There was one $p$ value when comparing OS of tumor size dichotomy, and the threshold of minimum $p$ value was set at $p<0.05, p<0.01, p<$ 0.001 , or $p<0.0001$. There were three and six $p$ values when comparing pairwise tumor size trichotomy and inquartation. To control multiplicity in multiple comparison, Bonferroni analysis is used for controlling the incidence of type I errors. Hence, the threshold of minimum $p$ value was set at $p<0.0167$, $p<0.01, p<0.001$, or $p<0.0001$ when selecting appropriate trichotomy cutoff and $p<0.0083, p<$ 0.001 , or $p<0.0001$ when selecting appropriate inquartation cutoff.

If multiple cutoffs meet the above standard, univariate analyses will be performed by using the Cox proportional hazards regression model, and hazard ratio (HR) will be considered as a criterion to assess the difference in survival. In contrast to the Kaplan-Meier method, Cox proportional hazards regression can provide an effect estimate by quantifying the difference in survival between tumor size groups. There was one HR value when comparing OS of tumor size dichotomy, and the highest one was screened according to the previous study [12]. A dummy variable was created when comparing OS of tumor size trichotomy and inquartation, and there existed two and three HR values, respectively. The highest last HR values (> last cutoff vs $\leq$ the first one) were screened.

\section{Clinicopathologic variables}

The tumor size was based on the largest dimension of the tumor in the resected specimen. Microvascular 
invasion (MVI) was defined as the presence of tumor cell clusters within the blood vessels lined by the endothelium including the branch of the portal vein, hepatic vein, or capsular vessel [16]. Tumor differentiation was assessed according to the Edmondson-Steiner grade. Tumor stage was determined according to the Barcelona Clinic Liver Cancer (BCLC) staging system and American Joint Committee on Cancer (AJCC) staging system (8th edition) [17, 18].

\section{Follow-up}

Patients were followed up by the serum levels of $\alpha$ fetoprotein (AFP), ultrasonography, and computed tomography/magnetic resonance imaging at 1 month after LR operation, then every 2 months in the first 6 months, and every 3 months at a later time. The OS was defined as the time interval between the day of the operation and death. The last follow-up data were collected until December 31, 2018.

\section{Statistical analysis}

Continuous values were expressed as mean \pm standard deviation (SD) or as median (range) and compared by using the $t$ test or Mann-Whitney $U$ test. Categorical variables were expressed as number (\%) and compared by using the chi-square or Fisher's exact test. The OS rates were generated by using the Kaplan-Meier method, and the differences were compared by log-rank test. Univariate analyses were performed by employing the Cox proportional hazards regression model. Statistical analyses were performed by using IBM SPSS software (version 19.0, SPSS Inc., Chicago, IL). A $p<0.05$ (twotailed) was considered as the threshold of significance.

\section{Results}

\section{Clinicopathologic characteristics}

The clinicopathologic characteristics of the 1760 solitary HBV-related HCC patients are summarized in Table 1. Most of these patients were male $(85.1 \%)$, and the mean age was 50.7 (SD 10.2). Over half of the patients (54.5\%) were detected with a positive HBVDNA (> $1000 \mathrm{IU} / \mathrm{mL}$ ). Half of the patients (47.3\%) were diagnosis of cirrhosis pathologically. There are only 583 (33.1\%) who had AFP levels $\geq 400 \mathrm{ng} / \mathrm{mL}$, and MVI incidence is $23.1 \%$. The mean tumor diameter was $5.55 \mathrm{~cm}$.

\section{Tumor overall survival outcomes}

Among all 1760 patients, the median survival time was 70 months. The 1-, 3-, and 5-year OS were 90.7\%, 75.9\%, and $57.8 \%$, respectively. Patients were classified into 11 groups based on tumor size with $1-\mathrm{cm}$ intervals, and the OS decreased with increasing tumor size (Fig. 1).
Table 1 The clinicopathologic factors of solitary HBV-related HCC patients who underwent initial hepatectomy $(n=1760)$

\begin{tabular}{ll}
\hline Parameter & Value \\
\hline Age, years & $50.7 \pm 10.2$ \\
Sex & \\
$\quad$ Male & $1497(85.1 \%)$ \\
$\quad$ Female & $263(14.9 \%)$ \\
a-Fetoprotein, ng/mL & \\
$\quad \leq 20$ & $726(41.2 \%)$ \\
$20-400$ & $451(25.6 \%)$ \\
$\geq 400$ & $583(33.1 \%)$
\end{tabular}

HBV DNA, IU/ml

$\leq 1000$

801 (45.5\%)

$>1000$

959 (54.5\%)

White blood cells, $10^{9} / \mathrm{L}$

$5.26 \pm 1.74$

Platelet count, $10^{9} / \mathrm{L}$

$152(23-479)$

Albumin, g/L

$41.7 \pm 3.74$

Total bilirubin, $\mu \mathrm{mol} / \mathrm{L}$

$13.4(3.3-45.4)$

Y-Glutamyl transferase, IU/L

$55.0(10-1175)$

Alkaline phosphatase, IU/L

$80.0(17-1155)$

ALBI grade

$\leq-2.63$

$1270(72.2 \%)$

$>2.63$

$490(27.8 \%)$

Blood loss, $\mathrm{mL}$

$<800$

$1650(93.8 \%)$

$\geq 800$

$110(6.2 \%)$

Tumor size, $\mathrm{cm}$

$5.55 \pm 3.48$

Differentiation degree

|/II

295 (16.8\%)

III/IV

$1465(83.2 \%)$

Microvascular invasion

Absent

$1354(76.9 \%)$

Present

406 (23.1\%)

AJCC stage

T1a

$121(6.9 \%)$

$\mathrm{T} 1 \mathrm{~b}$

$1250(71.0 \%)$

T2

389 (22.1\%)

$B C L C$ stage

0

$121(6.9 \%)$

A

$1639(93.1 \%)$

Tumor capsule

Incomplete/absent

$1232(70.0 \%)$

Complete

528 (30.0\%)

Cirrhosis

$\begin{array}{ll}\text { Absent } & 927(52.7 \%)\end{array}$

Present

$833(47.3 \%)$

Values shown are mean $\pm \mathrm{SD}$, median (range), or $n(\%)$ 


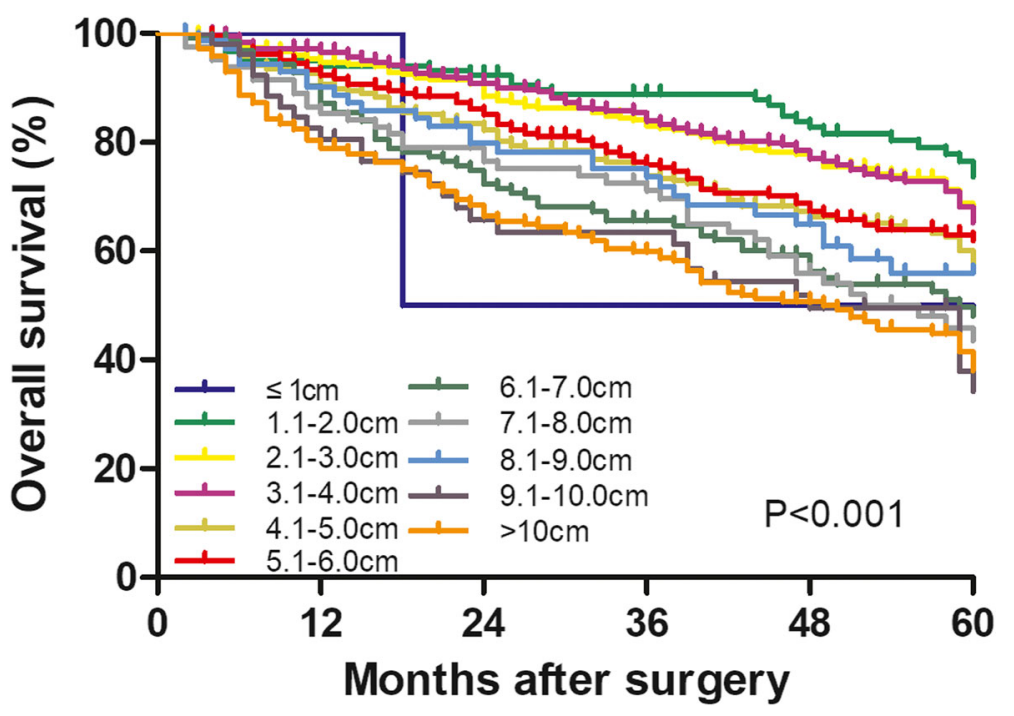

Fig. 1 Overall survival of patients with solitary HBV-related HCC following liver resection, classified by tumor size into 11 groups differing at $1.0-\mathrm{cm}$ intervals

Tumor size cutoffs screening based on minimum $p$ value of prognosis

To examine possible cutoffs of solitary HCC, the largest tumor diameters were subdivided by 10 dichotomy, 45 trichotomy, and 120 inquartation groups, and there were 10,45 , and 120 cutoffs after exhaustive search. The $p$ values of log-rank test for OS of each cutoff were calculated and cutoffs were screened.

As much as 8 from 10 cutoffs were screened when classified tumor diameters by dichotomy, and the minimum $p$ value was set at $p<0.0001$. The HR values of tumor size at these cutoffs for OS were compared, and the highest is 2.074 when size cutoff is $9 \mathrm{~cm}$ (Table 2). Similarly, there were 8 from 45 cutoffs which were screened when classifying tumor size by trichotomy, and the minimum $p$ value was set at $p<0.0001$ (Table 3). The HR values of tumor size at these cutoffs for OS were compared, and the highest last $\mathrm{HR}$ value is 2.79 when size cutoff is $3 / 9 \mathrm{~cm}$. However, there was no inquartation cutoff screened when the minimum $p$ value was set at $p<0.0083$.

Redefinition of tumor size groups and their characteristics We reclassified patients into three new categories: $\leq$ $3 \mathrm{~cm}(n=422),>3$ and $\leq 9 \mathrm{~cm}(n=1072)$, and $>9$ $\mathrm{cm}(n=266)$. The comparison of clinicopathologic characteristics among these three new classifications (Table 4) showed that the increase of tumor size was associated with the increase of AFP, white blood cell count (WBC), platelet count (PLT), $\gamma$-glutamyl transferase (GGT), alkaline phosphatase (ALP), volume of blood loss, MVI, tumor differentiation, and liver cirrhosis.

\section{Overall survival of the new three groups}

Based on these biological characteristics and prognostic findings, we suggested $3 / 9 \mathrm{~cm}$ could be appropriate cutoff for tumor size of solitary HBV-related HCC. The overall 1-, 3-, and 5-year survival rates were $94.5 \%, 84.5 \%$, and $69.0 \%$ in patients with $\mathrm{HCC} \leq 3$ $\mathrm{cm} ; 92.0 \%, 76.3 \%$, and $58.3 \%$ in patients with $\mathrm{HCC}>$ 3 and $\leq 9 \mathrm{~cm}$; and $79.3 \%, 60.5 \%$, and $37.4 \%$ in patients with $\mathrm{HCC}>9 \mathrm{~cm}$, respectively. The comparison

Table 2 The $p$ values of log-rank test and HR values for OS of each dichotomy size cutoff

\begin{tabular}{lll}
\hline Cutoffs & $\begin{array}{l}\text { Log-rank OS } \\
p \text { value }\end{array}$ & $\begin{array}{l}\text { Cox } \\
\text { HR-OS }(95 \% \mathrm{Cl})\end{array}$ \\
\hline $1 \mathrm{~cm}$ & 0.40435 & \\
$2 \mathrm{~cm}$ & 0.00016 & \\
$3 \mathrm{~cm}^{*}$ & $<0.0001$ & $1.702(1.408-2.059)$ \\
$4 \mathrm{~cm}^{*}$ & $<0.0001$ & $1.881(1.613-2.194)$ \\
$5 \mathrm{~cm}^{*}$ & $<0.0001$ & $1.87(1.615-2.164)$ \\
$6 \mathrm{~cm}^{*}$ & $<0.0001$ & $2.049(1.766-2.377)$ \\
$7 \mathrm{~cm}^{*}$ & $<0.0001$ & $1.968(1.683-2.302)$ \\
$8 \mathrm{~cm}^{*}$ & $<0.0001$ & $1.948(1.650-2.299)$ \\
$9 \mathrm{~cm}^{*}$ & $<0.0001$ & $2.074^{\#}(1.737-2.476)$ \\
$10 \mathrm{~cm}^{*}$ & $<0.0001$ & $2.013(1.662-2.439)$ \\
\hline $0 \mathrm{Coval}^{*}$ &
\end{tabular}

OS overall survival, $H R$ hazard ratio, $C l$ confidence interval

*The $p$ values of log-rank test for OS of size cutoff had significant statistical difference $(p<0.0001)$; " The highest HR value of Cox proportional analysis for OS 
Table 3 The $p$ values of log-rank test and HR values for OS of each trichotomy size cutoff

\begin{tabular}{|c|c|c|c|c|c|c|}
\hline \multicolumn{2}{|c|}{ Cutoffs (cm) } & \multicolumn{3}{|c|}{$p$ value of log-rank } & \multicolumn{2}{|l|}{$\mathrm{HR}(95 \% \mathrm{Cl})$ of Cox } \\
\hline A & $B$ & $\leq A$ vs. $A \sim B$ & $\leq \mathrm{A}$ vs. $>\mathrm{B}$ & $A \sim B$ vs. $>B$ & $A \sim B$ vs. $\leq A$ & $>$ B vs. $\leq \mathrm{A}$ \\
\hline 1 & 2 & 0.611280 & 0.417322 & 0.000224 & & \\
\hline 1 & 3 & 0.401394 & 0.424487 & $<0.0001$ & & \\
\hline 1 & 4 & 0.588828 & 0.327959 & $<0.0001$ & & \\
\hline 1 & 5 & 0.566227 & 0.277350 & $<0.0001$ & & \\
\hline 1 & 6 & 0.545619 & 0.222792 & $<0.0001$ & & \\
\hline 1 & 7 & 0.493309 & 0.263552 & $<0.0001$ & & \\
\hline 1 & 8 & 0.482870 & 0.257788 & $<0.0001$ & & \\
\hline 1 & 9 & 0.460243 & 0.289755 & $<0.0001$ & & \\
\hline 1 & 10 & 0.444595 & 0.325466 & $<0.0001$ & & \\
\hline 2 & 3 & 0.083743 & $<0.0001$ & $<0.0001$ & & \\
\hline 2 & 4 & 0.103040 & $<0.0001$ & $<0.0001$ & & \\
\hline 2 & 5 & 0.029683 & $<0.0001$ & $<0.0001$ & & \\
\hline 2 & 6 & 0.018186 & $<0.0001$ & $<0.0001$ & & \\
\hline 2 & 7 & 0.005548 & $<0.0001$ & $<0.0001$ & & \\
\hline 2 & 8 & 0.002914 & $<0.0001$ & $<0.0001$ & & \\
\hline 2 & 9 & 0.001960 & $<0.0001$ & $<0.0001$ & & \\
\hline 2 & 10 & 0.001138 & $<0.0001$ & $<0.0001$ & & \\
\hline 3 & 4 & 0.451643 & $<0.0001$ & $<0.0001$ & & \\
\hline 3 & 5 & 0.028445 & $<0.0001$ & $<0.0001$ & & \\
\hline 3 & 6 & 0.009799 & $<0.0001$ & $<0.0001$ & & \\
\hline 3 & 7 & 0.000557 & $<0.0001$ & $<0.0001$ & & \\
\hline 3 & $8^{*}$ & $<0.0001$ & $<0.0001$ & $<0.0001$ & $1.472(1.208-1.793)$ & $2.574(2.058-3.219)$ \\
\hline 3 & $9^{*}$ & $<0.0001$ & $<0.0001$ & $<0.0001$ & $1.497(1.23-1.82)$ & $2.79^{\#}(2.21-3.523)$ \\
\hline 3 & $10^{*}$ & $<0.0001$ & $<0.0001$ & $<0.0001$ & $1.542(1.27-1.874)$ & $2.781(2.176-3.554)$ \\
\hline 4 & 5 & 0.000843 & $<0.0001$ & 0.001334 & & \\
\hline 4 & 6 & 0.000214 & $<0.0001$ & $<0.0001$ & & \\
\hline 4 & $7^{*}$ & $<0.0001$ & $<0.0001$ & $<0.0001$ & $1.566(1.312-1.868)$ & $2.405(2.009-2.879)$ \\
\hline 4 & $8^{*}$ & $<0.0001$ & $<0.0001$ & $<0.0001$ & 1.63 (1.376-1.932) & $2.464(2.038-2.978)$ \\
\hline 4 & $9^{*}$ & $<0.0001$ & $<0.0001$ & $<0.0001$ & $1.646(1.395-1.944)$ & $2.67(2.184-3.263)$ \\
\hline 4 & $10^{*}$ & $<0.0001$ & $<0.0001$ & $<0.0001$ & $1.702(1.447-2.004)$ & $2.662(2.148-3.299)$ \\
\hline 5 & 6 & 0.074289 & $<0.0001$ & $<0.0001$ & & \\
\hline 5 & 7 & $<0.0001$ & $<0.0001$ & 0.000524 & & \\
\hline 5 & 8 & $<0.0001$ & $<0.0001$ & 0.001047 & & \\
\hline 5 & $9^{*}$ & $<0.0001$ & $<0.0001$ & $<0.0001$ & $1.602(1.352-1.9)$ & $2.42(2.004-2.922)$ \\
\hline 5 & 10 & $<0.0001$ & $<0.0001$ & 0.000794 & & \\
\hline 6 & 7 & $<0.0001$ & $<0.0001$ & 0.381256 & & \\
\hline 6 & 8 & $<0.0001$ & $<0.0001$ & 0.255359 & & \\
\hline 6 & 9 & $<0.0001$ & $<0.0001$ & 0.025411 & & \\
\hline 6 & 10 & $<0.0001$ & $<0.0001$ & 0.069108 & & \\
\hline 7 & 8 & 0.000275 & $<0.0001$ & 0.449406 & & \\
\hline 7 & 9 & $<0.0001$ & $<0.0001$ & 0.037663 & & \\
\hline 7 & 10 & $<0.0001$ & $<0.0001$ & 0.109361 & & \\
\hline
\end{tabular}


Table 3 The $p$ values of log-rank test and HR values for OS of each trichotomy size cutoff (Continued)

\begin{tabular}{|c|c|c|c|c|c|c|}
\hline \multicolumn{2}{|c|}{ Cutoffs $(\mathrm{cm})$} & \multicolumn{3}{|c|}{$p$ value of log-rank } & \multicolumn{2}{|c|}{ HR (95\% Cl) of Cox } \\
\hline A & $B$ & $\leq \mathrm{A}$ vs. $A \sim B$ & $\leq \mathrm{A}$ vs. $>\mathrm{B}$ & $A \sim B$ vs. $>B$ & $A \sim B$ vs. $\leq \mathrm{A}$ & $>$ B vs. $\leq \mathrm{A}$ \\
\hline 8 & 9 & 0.044308 & $<0.0001$ & 0.042670 & & \\
\hline 8 & 10 & $<0.0001$ & $<0.0001$ & 0.166143 & & \\
\hline 9 & 10 & $<0.0001$ & $<0.0001$ & 0.944208 & & \\
\hline
\end{tabular}

OS overall survival, $H R$ hazard ratio, $C l$ confidence interval

*The $p$ values of log-rank test for OS of size cutoff had significant statistical difference $(p<0.0001)$; ${ }^{\#}$ The highest HR value of Cox proportional analysis for OS

of the OS between any two subgroups showed statistical differences (all $p<0.001$ ) (Fig. 2).

\section{Discussion}

Tumor size is a key characteristic of HCC, and its classification is one of the most important issues for HCC treatment and prognosis. However, there are currently no uniform cutoff criteria for the size of HCC. A systematic review showed there are three kinds of criteria for small HCC alone [19]. Even in different stage systems, the criteria for the size of solitary HCC are inconsistent. In this study, we subdivided tumor size by $1-\mathrm{cm}$ intervals and analyzed the relationship between tumor size and the overall survival of 1760 patients with solitary HBVrelated HCC. Our results revealed a stepwise incremental deterioration in OS outcomes with increased tumor size, which is consistent with other studies $[10,11]$. Then we employed the minimum $p$ value method to screen the appropriate size cutoffs that could divide HCC tumor OS well.

Many previous studies showed that multiple dichotomy can divide tumor size well based on prognosis. The BCLC, AJCC, and Japan Integrated Staging Score (JIS) employ $2 \mathrm{~cm}$ as the cutoff for single HCC [17, 18, 20], while the Hong Kong Liver Cancer (HKLC) and Chinese Liver Cancer (CNLC) staging system use a cutoff with 5 $\mathrm{cm}[21,22]$. One previous study suggested multiple size cutoffs such as $2 \mathrm{~cm}, 3 \mathrm{~cm}, 4 \mathrm{~cm}, 5 \mathrm{~cm}, 8 \mathrm{~cm}$, and $10 \mathrm{~cm}$ have good discrimination for HCC prognosis [23]. In this study, similarly, dichotomy results of minimum $p$ value of OS showed that 8 among 10 cutoffs can divide tumor size into 2 groups well. These evidences indicated dichotomy of HCC tumor size might not reflect the biological nature of HCC. Among these cutoffs, the HR values of OS are compared, and $9 \mathrm{~cm}$ has the highest HR for OS. This is inconsistent with the result of a multicenter study indicating $2 \mathrm{~cm}$ has the highest HR for OS [12], which may be caused by different study population and treatment decisions in different countries or regions.

Then, we divided HCC tumors into 45 trichotomy groups. There are 8 cutoffs of size discriminated OS well when the minimum $p$ value was set at $p<$
0.0001. With the comparison of HR of these groups, we found that $3 / 9 \mathrm{~cm}$ cutoff groups have the highest HR value for OS. When we tried inquartation of tumor size, there were no cutoffs screened. Furthermore, the comparison of clinicopathologic characteristics of new classifications showed that the increase of tumor size was associated with biological characteristics. On the basis of these results, $3 / 9 \mathrm{~cm}$ could be an appropriate size cutoff for HCC tumor.

There are some similarities and differences with other studies. In one study of 857 patients with single HCC, $5 / 8 \mathrm{~cm}$ was suggested to be the cutoff of size after dividing $\mathrm{HCC}$ into 5 groups with 2-cm intervals and combining the adjacent groups with similar OS [10]. Another large retrospective study chose the controversial cutoff of $5 \mathrm{~cm}$ as the boundary of small and large HCC after a similar method [11]. As the initial criteria of small HCC, $5 \mathrm{~cm}$ was raised since the mid to late 1970s [24]. Along with the advances in radiographic diagnostic techniques and pathophysiology, smaller criteria such as $3 \mathrm{~cm}$ and $2 \mathrm{~cm}$ were proposed to replace the criteria of small HCC by many EastWest study groups. The size cutoff of $2 \mathrm{~cm}$ was raised from BCLC system in 2003 based on the data of the Liver Cancer Study Group of Japan (LCSGJ) and has been adopted in the BCLC and AJCC staging system (eight edition). However, many studies showed tumors up to $2 \mathrm{~cm}$ are accounted for a very small proportion of $\mathrm{HCC}$ and hard to analyze their pathobiological characteristics [25]. Moreover, studies based on pathobiological characteristics indicated that $3 \mathrm{~cm}$ in diameter is an important turning point of HCC development, where HCC transformed from relatively benign behavior to a more aggressive progression [6]. From a clinical standpoint, single HCC tumors up to $3 \mathrm{~cm}$ had a similar 3-year OS rate when treated by radiofrequency ablation (RFA), percutaneous ethanol injection (PEI), and surgical resection [26]. Thus, $3 \mathrm{~cm}$ as a cutoff of small HCC had a pathobiological and treatment significance.

With the development of research, the cutoff of large $\mathrm{HCC}$ tumor size was no longer confined to $5 \mathrm{~cm}$, which can be reflected in changes in criteria for liver 
Table 4 Comparison of clinicopathologic characteristics among three new classifications

\begin{tabular}{|c|c|c|c|c|c|c|}
\hline \multirow[t]{2}{*}{ Parameter } & \multirow{2}{*}{$\begin{array}{l}\leq 3 \mathrm{~cm} \\
(n=422)\end{array}$} & \multirow{2}{*}{$\begin{array}{l}3 \sim 9 \mathrm{~cm} \\
(n=1072)\end{array}$} & \multirow{2}{*}{$\begin{array}{l}>9 \mathrm{~cm} \\
(n=266)\end{array}$} & \multicolumn{3}{|l|}{$p$ value } \\
\hline & & & & $\leq 3$ vs. $3 \sim 9$ & $3 \sim 9$ vs. $>9$ & $\leq 3$ vs. $>9$ \\
\hline \multicolumn{7}{|l|}{ Age, years } \\
\hline$\leq 50$ & $212(50.2 \%)$ & 534 (49.8\%) & $139(52.3 \%)$ & 0.928 & 0.519 & 0.662 \\
\hline$>50$ & $210(49.8 \%)$ & $538(50.2 \%)$ & $127(47.7 \%)$ & & & \\
\hline \multicolumn{7}{|l|}{ Sex } \\
\hline Male & $346(82.0 \%)$ & $928(86.6 \%)$ & $223(83.8 \%)$ & 0.0303 & 0.293 & 0.604 \\
\hline Female & $76(18.0 \%)$ & 144 (13.4\%) & $43(16.2 \%)$ & & & \\
\hline \multicolumn{7}{|l|}{ AFP, $n g / m L$} \\
\hline$\leq 20$ & $183(43.4 \%)$ & 471 (43.9\%) & $72(27.1 \%)$ & $<0.001$ & $<0.001$ & $<0.001$ \\
\hline $20-400$ & $140(33.2 \%)$ & 249 (23.2\%) & $62(23.3 \%)$ & & & \\
\hline$\geq 400$ & $99(23.5 \%)$ & $352(32.8 \%)$ & $132(49.6 \%)$ & & & \\
\hline \multicolumn{7}{|c|}{ HBV DNA, IU/ml } \\
\hline$\leq 1000$ & $213(50.5 \%)$ & 488 (45.5\%) & $100(37.6 \%)$ & 0.0951 & 0.0236 & 0.00126 \\
\hline$>1000$ & $209(49.5 \%)$ & $584(54.5 \%)$ & $166(62.4 \%)$ & & & \\
\hline \multicolumn{7}{|c|}{ White blood cells, $10^{9} / \mathrm{L}$} \\
\hline$<4$ & $131(31.0 \%)$ & $236(22.0 \%)$ & $41(15.4 \%)$ & $<0.001$ & 0.0218 & $<0.001$ \\
\hline$\geq 4$ & $291(69.0 \%)$ & $836(78.0 \%)$ & $225(84.6 \%)$ & & & \\
\hline \multicolumn{7}{|c|}{ Platelet count, $10^{9} / \mathrm{L}$} \\
\hline$<100$ & $115(27.3 \%)$ & $193(18.0 \%)$ & $15(5.6 \%)$ & $<0.001$ & $<0.001$ & $<0.001$ \\
\hline$\geq 100$ & 307 (72.7\%) & 879 (82.0\%) & $251(94.4 \%)$ & & & \\
\hline \multicolumn{7}{|l|}{ Albumin, $g / L$} \\
\hline$<35$ & $10(2.4 \%)$ & $29(2.7 \%)$ & $14(5.3 \%)$ & 0.852 & 0.0545 & 0.0717 \\
\hline$\geq 35$ & $412(97.6 \%)$ & $1043(97.3 \%)$ & $252(94.7 \%)$ & & & \\
\hline \multicolumn{7}{|c|}{ Total bilirubin, $\mu \mathrm{mol} / \mathrm{L}$} \\
\hline$\leq 17.1$ & $314(74.4 \%)$ & 822 (76.7\%) & $205(77.1 \%)$ & 0.391 & 0.958 & 0.485 \\
\hline$>17.1$ & $108(25.6 \%)$ & $250(23.3 \%)$ & $61(22.9 \%)$ & & & \\
\hline \multicolumn{7}{|c|}{ Y-Glutamyl transferase, IU/L } \\
\hline$\leq 64$ & $300(71.1 \%)$ & $663(61.8 \%)$ & $62(23.3 \%)$ & $<0.001$ & $<0.001$ & $<0.001$ \\
\hline$>64$ & $122(28.9 \%)$ & 409 (38.2\%) & $204(76.7 \%)$ & & & \\
\hline \multicolumn{7}{|c|}{ Alkaline phosphatase, IU/L } \\
\hline$\leq 129$ & $410(97.2 \%)$ & 998 (93.1\%) & $181(68.0 \%)$ & 0.00362 & $<0.001$ & $<0.001$ \\
\hline$>129$ & $12(2.8 \%)$ & $74(6.9 \%)$ & $85(32.0 \%)$ & & & \\
\hline \multicolumn{7}{|l|}{ ALBI grade } \\
\hline$\leq-2.63$ & $321(76.1 \%)$ & 795 (74.2\%) & $154(57.9 \%)$ & 0.486 & $<0.001$ & $<0.001$ \\
\hline$>2.63$ & $101(23.9 \%)$ & 277 (25.8\%) & $112(42.1 \%)$ & & & \\
\hline \multicolumn{7}{|c|}{ Blood loss, mL } \\
\hline$<800$ & $417(98.8 \%)$ & $1024(95.5 \%)$ & $209(78.6 \%)$ & 0.00326 & $<0.001$ & $<0.001$ \\
\hline$\geq 800$ & $5(1.2 \%)$ & $48(4.5 \%)$ & $57(21.4 \%)$ & & & \\
\hline \multicolumn{7}{|c|}{ Differentiation degree } \\
\hline$|/| \mid$ & $105(24.9 \%)$ & $174(16.2 \%)$ & $16(6.0 \%)$ & $<0.001$ & $<0.001$ & $<0.001$ \\
\hline III/IV & $317(75.1 \%)$ & $898(83.8 \%)$ & $250(94.0 \%)$ & & & \\
\hline \multicolumn{7}{|c|}{ Microvascular invasion } \\
\hline Negative & $349(82.7 \%)$ & $830(77.4 \%)$ & $175(65.8 \%)$ & 0.0292 & $<0.001$ & $<0.001$ \\
\hline Positive & $73(17.3 \%)$ & $242(22.6 \%)$ & $91(34.2 \%)$ & & & \\
\hline
\end{tabular}


Table 4 Comparison of clinicopathologic characteristics among three new classifications (Continued)

\begin{tabular}{|c|c|c|c|c|c|c|}
\hline \multirow[t]{2}{*}{ Parameter } & \multirow{2}{*}{$\begin{array}{l}\leq 3 \mathrm{~cm} \\
(n=422)\end{array}$} & \multirow{2}{*}{$\begin{array}{l}3 \sim 9 \mathrm{~cm} \\
(n=1072)\end{array}$} & \multirow{2}{*}{$\begin{array}{l}>9 \mathrm{~cm} \\
(n=266)\end{array}$} & \multicolumn{3}{|l|}{$p$ value } \\
\hline & & & & $\leq 3$ vs. $3 \sim 9$ & $3 \sim 9$ vs. $>9$ & $\leq 3$ vs. $>9$ \\
\hline \multicolumn{7}{|l|}{ Tumor capsule } \\
\hline Incomplete/absent & $292(69.2 \%)$ & $735(68.6 \%)$ & $205(77.1 \%)$ & 0.861 & 0.00827 & 0.0309 \\
\hline Complete & $130(30.8 \%)$ & 337 (31.4\%) & 61 (22.9\%) & & & \\
\hline \multicolumn{7}{|l|}{ Cirrhosis } \\
\hline Absent & $157(37.2 \%)$ & $588(54.9 \%)$ & $182(68.4 \%)$ & $<0.001$ & $<0.001$ & $<0.001$ \\
\hline Present & $265(62.8 \%)$ & $484(45.1 \%)$ & $84(31.6 \%)$ & & & \\
\hline
\end{tabular}

transplantation. University of California, San Francisco (UCSF) criteria [27] and Up-to-Seven criteria [28] implied single tumors $\leq 6.5$ or $\leq 6 \mathrm{~cm}$ had a same prognosis with Milan criteria. Hangzhou criteria [29] and Fudan criteria [30] further broadened the size cutoff of single $\mathrm{HCC}$ tumor to $8 \mathrm{~cm}$ and $9 \mathrm{~cm}$. In this study, we reclassified patients into three new classifications: $\leq 3 \mathrm{~cm}$, $>3$ and $\leq 9 \mathrm{~cm}$, and $>9 \mathrm{~cm}$ according to the results of the minimum $p$ value of OS. The comparison of clinicopathologic characteristics among these three groups showed that the increase of tumor size was associated with multiple pathobiological features such as AFP, MVI, tumor differentiation, and liver cirrhosis. In addition, the comparison of the overall survival between any two subgroups showed a statistical difference (all $p<0.001$ ). These indicated that $3 / 9 \mathrm{~cm}$ as the boundary of small $\mathrm{HCC}$ and large $\mathrm{HCC}$ had a biological meaning and prognostic significance.

There are a few limitations to this study. Firstly, although the study population is large enough, this is a retrospective study and thus the results may not be generalized. A multicenter prospective study may be necessary to perform to validate our results. Secondly, all of the study population was HBV-related HCC since their characteristics are different from non-HBV-related HCC. Thirdly,
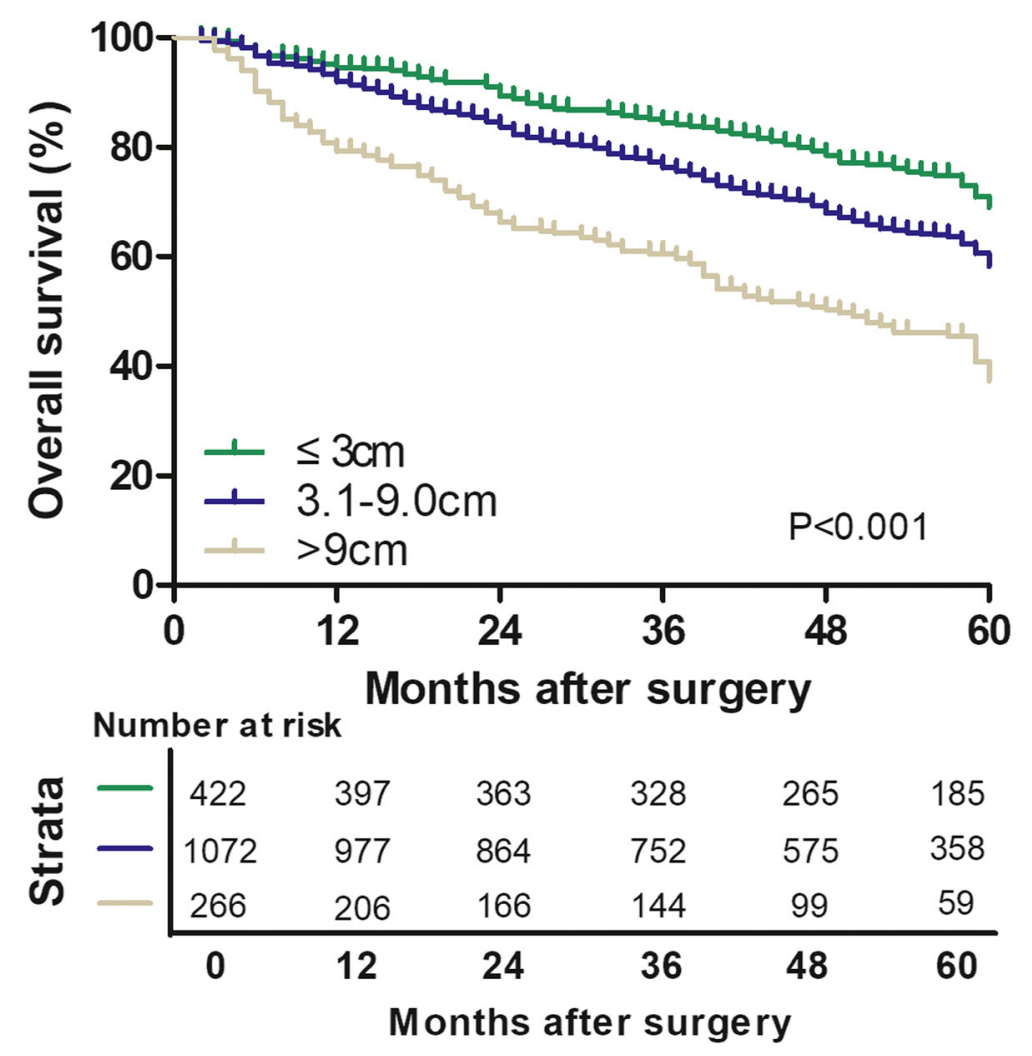

Fig. 2 Overall survival of patients with solitary HBV-related HCC classified by tumor size into three new groups 
insufficient patient volume of $\mathrm{HCC} \leq 1 \mathrm{~cm}$ may lead to be hard to work out further subclassification of HCC tumor size.

In conclusion, this study suggested that the tumor size with a cutoff of $3 \mathrm{~cm}$ and $9 \mathrm{~cm}$ in solitary HBV-related HCC patients was appropriate based on biological characteristics and prognostic significance.

\section{Supplementary information}

Supplementary information accompanies this paper at https://doi.org/10. 1186/s12957-020-01963-Z.

Additional file 1: Table Supplement. Table S1. The $p$ values of logrank test and HR values for RFS of each dichotomy size cutoff. Table S2. The $p$ values of log-rank test and HR values for RFS of each trichotomy size cutoff. Table S3. The $p$ values of log-rank test for RFS of each inquartation size cutoff.

\section{Acknowledgements}

The authors thank Mr. Xiaolong Liu, Mr. Xiangwen Liao, and Mr. Rui Jiang for their review of our study.

\section{Authors' contributions}

Jingfeng Liu, Weiping Zhou, and Pengfei Guo designed the study; Hongzhi Liu, Yuan Yang, Lei Wang, Chuanchun Chen, and Qizhen Huang contributed to the acquisition of data; Hongzhi Liu, Jianxing Zeng, Kongying Lin, and Yongyi Zeng contributed to the analysis of data; Hongzhi Liu and Yuan Yang drafted the article; Weiping Zhou revised the article. The authors read and approved the final manuscript.

\section{Funding}

Special fund of Fujian Development and Reform Commission (31010308), Fujian provincial medical center of hepatobiliary, key Clinical Specialty Discipline Construction Program of Fuzhou (201912002), and Fujian provincial health research talent training project (2019-1-85).

\section{Availability of data and materials}

All data generated or analyzed during this study are included in the articles.

\section{Ethics approval and consent to participate}

Not applicable

\section{Consent for publication}

Not applicable

\section{Competing interests}

The authors declare that they have no competing interests.

\section{Author details}

${ }^{1}$ Southeast Big Data Institute of Hepatobiliary Health, Mengchao Hepatobiliary Hospital of Fujian Medical University, Fuzhou 350025, People's Republic of China. ${ }^{2}$ Department of Hepatobiliary Surgery, Mengchao Hepatobiliary Hospital of Fujian Medical University, Xihong Road 312, Fuzhou 350025, People's Republic of China. ${ }^{3}$ Department of Hepatobiliary Surgery, Eastern Hepatobiliary Surgery Hospital, Second Military Medical University, Changhai Street 225, Shanghai 200438, People's Republic of China. ${ }^{4}$ Fuzhou Yixing Big Data Industry Investment Co., Ltd., Fuzhou 350025, People's Republic of China.

Received: 19 February 2020 Accepted: 17 July 2020

Published online: 24 July 2020

\section{References}

1. Organization WH: Liver cancer estimated incidence, mortality and prevalence worldwide in 2012. In.; 2015.
2. Kim E, Lisby A, Ma C, Lo N, Ehmer U, Hayer KE, Furth EE, Viatour P. Promotion of growth factor signaling as a critical function of $\beta$-catenin during HCC progression. Nat Commun. 2019;10(1):1909.

3. Mittal S, El-Serag HB. Epidemiology of HCC: consider the population. J Clin Gastroenterol. 2013;47:S2.

4. Tabrizian P, Jibara G, Shrager B, Schwartz M, Roayaie S. Recurrence of hepatocellular cancer after resection: patterns, treatments, and prognosis. Ann Surg. 2015;261(5):947-55.

5. Bruix J, Sherman M. Management of hepatocellular carcinoma: an update. Hepatology. 2011;53(3):1020-2.

6. Lu X-Y, Xi T, Lau W-Y, Dong H, Xian Z-H, Yu H, Zhu Z, Shen F, Wu M-C, Cong W-M. Pathobiological features of small hepatocellular carcinoma: correlation between tumor size and biological behavior. J Cancer Res Clin Oncol. 2011;137(4):567-75.

7. Ueno S, Kubo F, Sakoda M, Hiwatashi K, Tateno T, Mataki Y, Maemura K, Shinchi H, Natsugoe S, Aikou T. Efficacy of anatomic resection vs nonanatomic resection for small nodular hepatocellular carcinoma based on gross classification. J Hepato-Biliary-Pancreat Surg. 2008;15(5):493-500.

8. Fang K-C, Kao W-Y, Su C-W, Chen P-C, Lee P-C, Huang Y-H, Huo T-I, Chang C-C, Hou M-C, Lin H-C: The prognosis of single large hepatocellular carcinoma was distinct from Barcelona Clinic Liver Cancer stage A or B: the role of albumin-bilirubin grade. Liver cancer 2018.

9. Zhong J-H, Pan L-H, Wang Y-Y, Cucchetti A, Yang T, You X-M, Ma L, Gong $W-F$, Xiang B-D, Peng N-F. Optimizing stage of single large hepatocellular carcinoma: a study with subgroup analysis by tumor diameter. Medicine. 2017;96:15.

10. Liu L, Zhang Q-S, Pan L-H, Zhong J-H, Qin Z-M, Wang Y-Y, Qin H-G, Gong W-F, Qi L-N, Xiang B-D. Subclassification of patients with solitary hepatocellular carcinoma based on post-hepatectomy survival: a large retrospective study. Tumor Biol. 2016;37(4):5327-35.

11. Hwang S, Lee Y-J, Kim K-H, Ahn C-S, Moon D-B, Ha T-Y, Song G-W, Jung D$\mathrm{H}$, Lee $\mathrm{S}-\mathrm{G}$. The impact of tumor size on long-term survival outcomes after resection of solitary hepatocellular carcinoma: single-institution experience with 2558 patients. J Gastrointest Surg. 2015;19(7):1281-90.

12. Shindoh J, Andreou A, Aloia TA, Zimmitti G, Lauwers GY, Laurent A, Nagorney DM, Belghiti J, Cherqui D, Poon RT-P. Microvascular invasion does not predict long-term survival in hepatocellular carcinoma up to $2 \mathrm{~cm}$ : reappraisal of the staging system for solitary tumors. Ann Surg Oncol. 2013; 20(4):1223-9.

13. Li Y-W, Qiu S-J, Fan J, Zhou J, Gao Q, Xiao Y-S, Xu Y-F. Intratumoral neutrophils: a poor prognostic factor for hepatocellular carcinoma following resection. J Hepatol. 2011;54(3):497-505.

14. Liao R, Sun J, Wu H, Yi Y, Wang J-X, He H-W, Cai X-Y, Zhou J, Cheng Y-F, Fan J. High expression of IL-17 and IL-17RE associate with poor prognosis of hepatocellular carcinoma. J Exp Clin Cancer Res. 2013;32(1):3.

15. Wang L, Ke Q, Deng M-J, Huang $X$, Zeng J-X, Liu H-Z, Yang Y, Zeng Y-Y, Zhou W-P, Liu J-F. Adjuvant transarterial chemoembolization for patients with hepatocellular carcinoma after radical hepatectomy: a real world study. Scand J Gastroenterol. 2019:54(11):1403-11.

16. Cong W-M, Bu H, Chen J, Dong H, Zhu Y-Y, Feng L-H, Chen J, Committee G. Practice quidelines for the pathological diagnosis of primary liver cancer: 2015 update. World J Gastroenterol. 2016;22(42):9279.

17. EASL Clinical Practice Guidelines. Management of hepatocellular carcinoma. J Hepatol. 2018;69(1):182-236.

18. Amin MB, Greene FL, Edge SB, Compton CC, Gershenwald JE, Brookland RK, Meyer L, Gress DM, Byrd DR, Winchester DP. The eighth edition AJCC Cancer Staging Manual: continuing to build a bridge from a populationbased to a more "personalized" approach to cancer staging. CA Cancer J Clin. 2017:67(2):93-9.

19. Chen Z-H, Zhang X-P, Wang H, Chai Z-T, Sun J-X, Guo W-X, Shi J, Cheng SQ: Effect of microvascular invasion on the postoperative long-term prognosis of solitary small HCC: a systematic review and meta-analysis. HPB 2019

20. Kudo M, Chung H, Haji S, Osaki Y, Oka H, Seki T, Kasugai H, Sasaki Y, Matsunaga T. Validation of a new prognostic staging system for hepatocellular carcinoma: the JIS score compared with the CLIP score. Hepatology. 2004;40(6):1396-405

21. Yau T, Tang V-Y, Yao T-J, Fan S-T, Lo CM, Poon RT. Development of Hong Kong Liver Cancer staging system with treatment stratification for patients with hepatocellular carcinoma. Gastroenterology. 2014;146(7):1691-1700. e1693. 
22. Zhou J, Sun H-C, Wang Z, Cong W-M, Wang J-H, Zeng M-S, Yang J-M, Bie P, Liu L-X, Wen T-F. Guidelines for diagnosis and treatment of primary liver cancer in China (2017 edition). Liver cancer. 2018;7(3):235-60.

23. Zhang H, Yuan S-X, Dai S-Y, Zhang J-M, Huang X, Lu C-D, Lu J-H, Wu F-Q, Lau WY, Wu M-C. Tumor size does not independently affect long-term survival after curative resection of solitary hepatocellular carcinoma without macroscopic vascular invasion. World J Surg. 2014;38(4):947-57.

24. Cong W-M, Wu M-C. Small hepatocellular carcinoma: current and future approaches. Hepatol Int. 2013;7(3):805-12.

25. Farinati F, Sergio A, Baldan A, Giacomin A, Di Nolfo MA, Del Poggio $P$, Benvegnu L, Rapaccini G, Zoli M, Borzio F, et al. Early and very early hepatocellular carcinoma: when and how much do staging and choice of treatment really matter? A multi-center study. BMC Cancer. 2009;9:33.

26. Hasegawa K, Kokudo N, Makuuchi M, Izumi N, Ichida T, Kudo M, Ku Y, Sakamoto M, Nakashima O, Matsui O, et al. Comparison of resection and ablation for hepatocellular carcinoma: a cohort study based on a Japanese nationwide survey. J Hepatol. 2013;58(4):724-9.

27. Yao F, Xiao L, Bass N, Kerlan R, Ascher N, Roberts J. Liver transplantation for hepatocellular carcinoma: validation of the UCSF-expanded criteria based on preoperative imaging. Am J Transplant. 2007;7(11):2587-96.

28. Mazzaferro V, Llovet JM, Miceli R, Bhoori S, Schiavo M, Mariani L, Camerini T, Roayaie S, Schwartz ME, Grazi GL. Predicting survival after liver transplantation in patients with hepatocellular carcinoma beyond the Milan criteria: a retrospective, exploratory analysis. The lancet oncology. 2009;10(1): $35-43$.

29. Zheng S-S, Xu X, Wu J, Chen J, Wang W-L, Zhang M, Liang T-B, Wu L-M. Liver transplantation for hepatocellular carcinoma: Hangzhou experiences. Transplantation. 2008;85(12):1726-32.

30. Fan J, Yang G-S, Fu Z-R, Peng Z-H, Xia Q, Peng C-H, Qian J-M, Zhou J, Xu Y, Qiu S-J, et al. Liver transplantation outcomes in 1,078 hepatocellular carcinoma patients: a multi-center experience in Shanghai, China. J Cancer Res Clin Oncol. 2009;135(10):1403-12.

\section{Publisher's Note}

Springer Nature remains neutral with regard to jurisdictional claims in published maps and institutional affiliations.

Ready to submit your research? Choose BMC and benefit from:

- fast, convenient online submission

- thorough peer review by experienced researchers in your field

- rapid publication on acceptance

- support for research data, including large and complex data types

- gold Open Access which fosters wider collaboration and increased citations

- maximum visibility for your research: over $100 \mathrm{M}$ website views per year

At $\mathrm{BMC}$, research is always in progress.

Learn more biomedcentral.com/submissions 